Int. J. Plant Sci. 169(1):23-38. 2008.

(c) 2008 by The University of Chicago. All rights reserved.

1058-5893/2008/16901-0003\$15.00 DOI: $10.1086 / 523361$

\title{
EXPLAINING EVOLUTIONARY SHIFTS BETWEEN BEE AND HUMMINGBIRD POLLINATION: CONVERGENCE, DIVERGENCE, AND DIRECTIONALITY
}

\author{
James D. Thomson ${ }^{1, *}$ and Paul Wilsont \\ *Department of Ecology and Evolutionary Biology, University of Toronto, Toronto, Ontario M5S 3G5, Canada, and Rocky Mountain \\ Biological Laboratory, Crested Butte, Colorado 81224-0519, U.S.A.; and tDepartment of Biology, \\ California State University, Northridge, California 91330-8303, U.S.A.
}

\begin{abstract}
In certain angiosperm genera, closely related species have diverged from one another to converge on different pollination syndromes, whereas species with intermediate phenotypes are rare or absent. Convergent conformity to syndromes implies the existence of "evolutionary attractors" toward which phenotypes are drawn; divergent breaks from conformity show that populations can escape one attractor and be drawn to another. We discuss how these two opposed processes can be reconciled for the special case of evolutionary transitions between bee pollination and hummingbird pollination. In this case, a third phenomenon, the directional bias in favor of transitions from melittophily to ornithophily, also needs explanation. Older treatments chiefly ascribed convergence to cognitive and morphological properties of pollinators and ascribed transitions to geographical differences in pollinator availability. Those treatments did not specifically address what factors would overcome and disrupt the stabilizing selection that would be expected to preserve the pollination syndrome of a plant species. Here, we focus on possible contributors to destabilization, especially considering the possible roles of (1) differences among pollinators in pollen-transfer efficiency, (2) mutations with large effects on floral phenotypes, and (3) losses of function in the biochemical pathways that produce floral pigments. We conclude that all of these can influence the evolution of pollinator transitions but that the process usually needs to be initiated by external ecological factors that change the visitation rates of pollinators. We discuss the roles of particular floral characters in several plant genera that have undergone transitions. We expect that transitions reach completion through a "centripetal" process of selection that incrementally recruits changes in multiple characters.
\end{abstract}

Keywords: evolutionary transitions, Mimulus, Penstemon, pollination syndromes.

\section{Introduction}

Building on the natural history of pollination pioneered by Köhlreuter (1761-1766) and Sprengel (1793), Darwin (1862) illustrated his theory of evolution by showing that many floral characters can be interpreted as specific adaptations for service by various kinds of pollinating animals. Static views of function take on a dynamic dimension if one considers closely related plant species whose flowers differ in multiple characters because they are adapted to different pollinators. In such cases, we say that an evolutionary pollinator transition, or pollinator shift, has occurred. Such shifts can exemplify several evolutionary processes: adaptation, divergence from an ancestral mode of life, convergence toward a common functional phenotype, and the maintenance of reproductive isolation. Here, we focus on the circumstances that promote one type of evolutionary transition between "pollination syndromes," namely, shifts between adaptation to pollination by Hymenoptera, especially bees (the melittophily syndrome), and adaptation to pollination by hummingbirds (one type of ornithophily).

Such shifts may be a special case among pollinator transitions because the applicability of the pollination syndrome concept is greater here than in much of the rest of the angiosperms

1 Author for correspondence; e-mail: jthomson@zoo.utoronto.ca. Manuscript received February 2007; revised manuscript received June 2007.
(Fenster et al. 2004). Still, we believe that our narrow focus is warranted for several reasons. (1) Such shifts have occurred repeatedly, more than 100 times in western North America alone (Stebbins 1989; Grant 1994; Wilson et al. 2007). Importantly, species that conform to distinctly different pollination syndromes can be close relatives, even sister species. (2) There are active research programs on several genera displaying such shifts, including Penstemon, Mimulus, Ipomoea, Costus, Aquilegia, Silene, and Salvia (fig. 1). As these research programs mature, we expect generalities to emerge. In this review, we relate findings concerning these genera and synthesize them into a common explanation. Research on other types of shifts is patchily distributed, and a search for generality is probably premature. (3) Adaptation to bees or hummingbirds seems to produce multicharacter phenotypic discontinuities that correspond to cleanly separated pollination syndromes. For example, ordinations of Penstemon species based on floral characters yield clear clusters of melittophiles and ornithophiles (Wilson et al. 2004).

Pollination syndromes-defined as suites of floral characters that are adaptations to one kind of pollinator or anotherare important in our account of transitions. Probably for as long as the syndrome concept has existed, its architects and defenders have warned against oversimplification (Müller and Delpino 1871; Baker 1963; Stebbins 1970; Faegri and van der Pijl 1979). Nevertheless, the telegraphic condensations in textbooks have left students with the simplistic impression that most flowers 




Fig. 1 Flowers seemingly adapted to bee and bird pollination in six genera. A, Melittophilous Penstemon strictus (photo: J. Thomson). B, Ornithophilous Penstemon barbatus (photo: J. Thomson). C, Melittophilous Mimulus lewisii (photo: D. Schemske). D, Ornithophilous Mimulus cardinalis (photo: D. Schemske). E, Melittophilous Ipomoea purpurea (photo: M. Rausher). F, Ornithophilous Ipomoea quamoclit (photo: M. Rausher). G, Melittophilous Costus malortieanus (photo: D. Schemske). H, Ornithophilous Costus pulverulentus (photo: D. Schemske). I, Melittophilous Aquilegia saximontana (photo: J. Whittall). J, Aquilegia formosa (photo: S. Hodges). K, Entomophilous Silene caroliniana (photo: J. Antonovics and M. Hood). L, Ornithophilous Silene virginica (photo: J. Antonovics and M. Hood). 
can be classified nonhierarchically into categories pollinated by beetles, flies, carrion flies, bees, moths, butterflies, birds, and bats (the text by Simpson [2006] is a recent example). In fact, many animal-pollinated flowers present rewards openly and advertise them with cues that are accessible to many animals. Such flowers tend to attract insects from several orders and can be more or less successfully pollinated by most of them (Herrera 1996; Waser et al. 1996). Such generalized flowers present a variety of characters, and they resist functional categorization into pollination syndromes. In contrast, other taxa conform well to syndrome characterizations in that their morphologies appear to be adapted to pollination by animals of narrower taxonomic groups (e.g., single orders or families) or functional groups (e.g., long-tongued and large-bodied nectar feeders; Fenster et al. 2004). Such plants may be in the minority, and even when a species' conformity to a syndrome indicates a history of adaptation to a particular type of pollinator, it may be visited and successfully pollinated by other types (Faegri and van der Pijl 1979; Ollerton 1996; Mayfield et al. 2001). Syndromes are most convincingly revealed by convergent evolution, but even here there is a problem: differently endowed lineages may adapt to the same pollinators in ways that do not produce convergence, although those changes may be comprehensible given the initial conditions. Some authors find syndromes generally inapplicable to the systems they know best (e.g., Corbet 2006), but we find them useful in the more restricted context considered here (see Armbruster et al. 2000; Thomson et al. 2000; Fenster et al. 2004).

In this article, we hope to extend and enrich classical evolutionary explanations for clear-cut, qualitative, evolved shifts out of melittophily (the bee-pollination syndrome) and into ornithophily (the bird-pollination syndrome). In considering such transitions, Grant (1994) emphasized the biogeographical history of range extensions that brought hummingbirds into contact with bee-pollinated progenitors; he also invoked a positive feedback process at the community level, whereby the presence of some ornithophilous taxa would pave the way for subsequent shifts by melittophiles, simply by ensuring that hummingbirds would be regular members of such communities. Stebbins (1989) concentrated on changes in progenitor lineages that would serve as preadaptations for bird pollination, including the colonization of wetter habitats and the adoption of perennial life histories. He inferred that these characteristics were important preconditions for hummingbird pollination because they are frequently associated with it. These older explanations, therefore, invoked factors that could bring about frequent contacts between hummingbirds and melittophilous plants that had the potential to shift. Those conditions probably encourage shifts, but we find them incomplete: They do not explain what could overcome the strong niche conservatism that we would expect in plants that are well adapted to one sort of pollinator. In our view, conformity to a syndrome is maintained by stabilizing selection, and transitions occur only when something happens to destabilize the interdependence of plant and pollinator. Grant (1994) and Stebbins (1989) did not address this requirement of destabilization. It is our main focus.

We begin by proposing some metaphorical language for discussing the convergence of floral phenotypes toward pollination syndrome attractors. Then, we review models that show how differences in the efficiency of pollen transfer by bees and birds could establish a switch point that could divert a lineage from melittophily to ornithophily, and we discuss ecological circumstances that could trigger such switches. Next, we consider the sources and kinds of genetically based variation in floral traits that are involved in shifts from bee to bird pollination. Recognizing that new mutations of large effect are implicated in some bee-to-bird transitions, we ask whether such mutations are necessary in general. We then consider why beeto-bird transitions strongly outnumber transitions in the opposite direction. We follow this by some reflections on the multicharacter nature of the difference between melittophiles and ornithophiles. Finally, we briefly consider the applicability of our approach to broader questions: transitions among pollination systems other than Hymenoptera and hummingbirds, and evolutionary transitions in general.

\section{Metaphors for Transitional and Nontransitional Changes: Evolutionary Vortices and Adaptive Wandering}

Recognizing that the contrast between melittophily versus ornithophily (examples in fig. 1) may represent an extraordinarily clear-cut distinction between syndromes, it is worth mentioning as a point of contrast how we think generalist flowers might diversify without becoming specialized. Unlike the dynamics that we want to focus on here, it may be more common for floral phenotypes to respond to pollinator-driven selection by what we have called "adaptive wandering" (Wilson and Thomson 1996).

When flowers diversify by adaptive wandering, plants in geographically separate populations diverge phenotypically in response to different selection regimes imposed by local differences in the pollinator communities they experience (as in the geographic mosaic of Thompson 1994). They adapt to their local pollinators; this adaptation results in wandering because the local differences are too slight or too brief to cause the flowers to evolve any mechanisms that exclude other pollinators upon secondary contact. Lilies in the genus Calochortus section Mariposa are varied in color patterns, petal hairs, and the shape of nectar glands. Indeed, various species of pollinators respond differently to the different species of mariposa lilies, but the plants have not permanently specialized on different pollinators, and we cannot sensibly explain the diversity among mariposa lilies by seeking pollinator shifts (Dilley et al. 2000). Adaptive wandering results in taxonomically noteworthy variation among species that is driven by local adaptation, not by genetic drift, but it does not involve a shift to a new functional group of pollinators (sensu Fenster et al. 2004). It is not a coherent change in strategy. The adaptive adjustments that do take place are likely to be transient, reversible, and idiosyncratic; they do not converge toward a different syndrome. Like floating logs pushed around on the surface of the ocean by shifting winds and currents, the phenotypes of these populations are nudged about in multivariate character space, but the journey lacks structure and predictability. One population might be influenced by a bee that has an arbitrary preference for distinctive brown spots, another by a beetle that prefers hairy petals. In time, however, those pollinators give way to others; although the flowers have diverged, the divergence has not resulted in the exclusion or discouragement of any subsequent type of pollinator. The pattern reflects little more than local 
adaptation plus geographic heterogeneity in the selective environment.

In contrast, bee-to-bird shifts are more deterministic, and the multicharacter syndromes seem more like specialized strategies. The lineages have gravitated toward predefined attractors. Rather than resembling logs buffeted by unstructured Brownian currents, these phenotypes are like logs that have drifted into fixed whirlpools or vortices (Gilpin and Soule 1986), where they tend to become entrained by a kind of stabilizing selection. In multivariate character space, these phenotypes tend to be drawn toward conformity with particular pollination syndromes by a coherent set of changes in a predictable set of characters. Importantly, the approach toward a syndrome involves two sorts of phenotypic change, which Faegri and van der Pijl (1979, p. 126) term "positive" and "negative." Positive adaptations are directed to attracting and using the primary pollinator type, whereas negative adaptations lead toward repelling or excluding secondary, less desirable pollinators (Castellanos et al. 2004).

We like the metaphor of the vortex, which Gilpin and Soule (1986) used to describe the interacting factors leading to population extinction. Other metaphorical language is available for progressive change toward alternative attractors. Community ecologists sometimes speak of "alternative stable states" or "basins of attraction" (Beisner et al. 2003), and many comparative biologists have freely borrowed Sewall Wright's metaphor of "adaptive peaks" (Armbruster 1990; Losos 1992), which is the gravitational inversion of basins and vortices. The vortex metaphor is a good catchall that incorporates both genetic processes and ecological circumstances and shows how they interact to produce a particular outcome. Because it is not burdened by as much past usage as other metaphors and because it is unassociated with any particular model of genetic control, we hope that it will encourage fresh thought. Whether a population gets drawn into a syndrome vortex, we believe, depends not only on genetics and floral phenotypes but also on complicated interactions and feedbacks that ramify through the entire plant-pollinator community, as well as on stochasticity. In this sense, the factors that draw a population toward a syndrome are similar in complexity to those that can lead a population toward extinction. Finally, the vortex metaphor lends itself to considering why one vortex may be weaker than another, i.e., easier for a species to escape from. This notion is useful in considering directional biases in pollinator shifts.

Within a single pollination vortex, there may be plenty of multivariate character space for bounded adaptive wandering. A melittophilous lineage of flowers may diversify in response to selection exerted by different communities of bees on different populations. In such a case, we might expect to see more variation in less essential characters, such as nectar guides, scents, and fringing of petals, and less variation in the less decorative characters needed for retaining and exploiting bees. These would include the reward characters most important to securing visits (Waser et al. 1996), such as nectar quantity, concentration, and composition, and the floral geometry needed to ensure anther and stigma contacts. Thus, selection would keep the various species of the lineage in the vortex while permitting them to wander adaptively. In contrast, a shift out of the melittophily vortex into the ornithophily vortex would require escaping from those stabilizing forces and coming under the influence of a qualitatively new attractor.

\section{Differences in Pollinator Quality as Well as Quantity: Lessons from Penstemons}

Our thinking about shifts between melittophily and ornithophily has been inspired by penstemons (Thomson et al. 2000; Wilson et al. 2006; fig. $1 A, 1 B$ ). In this group, there have been numerous transitions in which bee-to-bird shifts have been marked by multicharacter convergence toward the hummingbird floral syndrome (Wolfe et al. 2006; Wilson et al. 2007). Our proffered evolutionary scenario for transitions from bee to hummingbird pollination rests importantly on differences between bees and birds in the quality of pollination ("efficiencies" or "efficacies") as well as the quantity of pollination ("visitation rates"). The transition we envision is outlined briefly as follows. Ancestral penstemons are adapted to bees (including pollen-collecting and therefore beelike masarid wasps), even though bees transfer relatively low proportions of the pollen that they remove from anthers. These melittophilous penstemons are not adapted to birds and are not particularly attractive to them. Therefore, bird visits are infrequent, but even without adaptation to birds, when a hummingbird does visit a patch of flowers, it delivers a high proportion of the pollen it removes. Given a strong enough difference in the pollendelivery efficiencies of two covisiting pollinators, it can be shown that the less efficient one may become a detrimental, pollen-wasting parasite if visits by the better one are frequent enough (Thomson and Thomson 1992; Thomson 2003). The relative numbers of visits by the two pollinators establish a threshold at which a pollinator's contribution switches from beneficial to parasitic. We propose that a change in ecological circumstances can increase the frequency of bird visits enough to cross this threshold, thereby destabilizing selection and bumping the floral phenotype out of the melittophily vortex and into the ornithophily vortex. If the new condition persists for long enough, selection will favor characters that make the flowers better suited to bird pollination and less attractive to bees. Those changes will effectively lower the threshold level of bird visits, providing a positive feedback that augments the superiority of ornithophily and makes reversal unlikely.

The clade we call "penstemons" includes the large genus Penstemon and the smaller sister genera Keckiella, Chionophila, Nothochelone, and Chelone (Wolfe et al. 2002). Essentially all the 284 species are melittophiles or hummingbird ornithophiles, and there is little ambiguity regarding these assignments. The two syndromes form distinct clusters in an ordination of 49 species (Wilson et al. 2004); yet, even among the species that we refer to as ornithophiles, there is variation in whether bees are retained as copollinators or excluded from access to nectaries. Field observations confirm that hummingbirds are prominent visitors to plants conforming to ornithophily and that they are very low-frequency visitors to melittophiles. Of the 284 species, 41 conform more or less to the hummingbird syndrome. Phylogenetic analyses suggest as many as 21 separate transitions toward ornithophily, and certainly no fewer than 10 (Wilson et al. 2007). There is no evidence for reversals, although reversal is a fairly difficult phenomenon to rule out. In addition, there are few if any species that have evolved toward other kinds of pollinators: just one clade of two species that may use bee flies along with bees and one species that may use butterflies along with bees (Wilson et al. 2007). Both the 
frequency and the directionality of shifts to hummingbird pollination are striking phenomena that demand explanation.

We have explored a mechanistic hypothesis to account for a pollen-transfer efficiency difference between bees and birds (Castellanos et al. 2003), based on differences in how these animals treat pollen. Depending on the size of a penstemon flower and the size of a bee visitor, anthers deposit pollen on the dorsal surfaces of the face, head, or thorax, and stigmas receive pollen from these same regions. Female bees groom while foraging, sweeping grains from the valuable dorsal surfaces into corbiculae or scopae on the legs and undersides of the body. Surely, pollen that is moistened and packed into a corbicular pellet can no longer participate in pollination, and the chances also seem slim that a pollen grain in the ventral abdominal scopa of an Osmia would reach a penstemon stigma. Because the collected pollen is fed to larvae, natural selection has endowed bees with highly effective grooming and structures and behaviors for gathering up and retaining large quantities of pollen. To hummingbirds, however, pollen is useless. They have no specialized pollen-grooming structures, and they tend to preen only between foraging bouts. This difference in grooming behavior may contribute to the seeming ease and the unidirectionality of transitions from melittophily to ornithophily in penstemons. One confirmatory finding is that the anthers of ornithophilous penstemons tend to open more widely and present pollen more freely than those of closely related melittophilous species (Castellanos et al. 2006), as would be expected if birds were less wasteful of pollen.

Simple bookkeeping models of pollen grain fates (Thomson and Thomson 1992) consider how male reproductive success (i.e., pollen export to stigmas) accrues when a plant is visited by varying numbers of two pollinator types, one wasteful and one efficient. If visits by the more efficient pollinator are rare, the more wasteful pollinator will serve the plant's interests as a beneficial mutualist. If, however, visits by the more efficient pollinator become more frequent, a threshold can be reached beyond which visits by the more wasteful pollinator actually reduce successful pollen export. At that point, any genetic variants that deter visits by the wasteful pollinator would be favored, as would any variants that improve the flower's fit or attractiveness to the less wasteful pollinator. For example, red colors might spread by deterring bees that have become conditional parasites (Raven 1972); improvements such as exserting the anthers and stigma probably make birds less wasteful transporters of pollen (Castellanos et al. 2004).

In other words, we envision the following scenario for pollinator transitions in flowers like those of penstemons. An ancestral population is adapted to pollination by large bees and displays the appropriate syndrome characters. Hummingbirds may be occasional visitors-these inquisitive animals frequently investigate flowers that do not conform to the "legitimate" syndrome-but visits are inconsequentially rare because the birds find the nectar offerings too meager. Therefore, bee pollination continues to exert stabilizing selection on the bee syndrome characters. The crucial initiator is some ecological change that shifts the bee-to-bird balance: either bees begin visiting less or birds begin visiting more. The former dominance of bees is destabilized. New directional selection then acts on standing genetic variation in floral characters to gradually produce conformity to the bird syndrome. Later, bees may return to prominence in the visitor assemblage, but there is selection to discourage and exclude them after birds have become reliable pollinators. With the increase in hummingbird pollination, visits by bees have crossed the threshold from being beneficial to being parasitic. The ornithophiles acquire antibee adaptations in addition to probird adaptations (Castellanos et al. 2004). Bees can no longer extract nectar easily, and the position of sexual organs no longer fits their bodies. The progression toward ornithophily is ratchetlike.

Our explanation has at least two weak points concerning testability. First, it is hard to demonstrate numerically whether the difference in pollen wastage between bees and birds is large enough to reach the threshold point where bee visits become parasitic. The model parameters that determine that threshold elude simple empirical measurement, partly because it is hard to track the fates of pollen grains as they move through the very messy process of pollination. Considering the melittophilous Penstemon strictus as a stand-in for an ancestral melittophile, Castellanos et al. (2003) confirmed that hummingbirds could remove enough pollen from anthers to be important pollinators. Total pollen deposition by birds did not exceed that by bees, and removal by birds was slightly lower, so those measurements fell slightly short of showing that birds are already better pollinators than bees. However, total deposition was recorded from short pollen carryover trials of only 15 recipient flowers; given the flatter pollen carryover curves conferred by birds, a longer series of recipients probably would have shown birds to be more efficient. Figure 2 gives a calibrated graphical extrapolation for how pollen carryover curves could translate into differences in male reproductive success. Unfortunately, repeating the experiment with longer sequences of recipients would be prohibitively tedious and probably impossible for wild-caught bees because the bees do not behave naturally in flight cages after they are well fed. The flatter carryover functions of birds may also produce higher-quality pollination because a greater proportion of grains removed from a flower will be transported to a different plant as opposed to being geitonogamously deposited. Another complication of this experiment is that $P$. strictus flowers have wide mouths that permit birds to approach laterally, rather than being constrained to probe straight in, along the principal floral axis (Castellanos et al. 2004). Had we chosen a melittophilous species with a narrower corolla, stigmatic contacts might have been more frequent. So, birds may not be better pollinators than bees on a per-visit basis to a bee-adapted penstemon, but they are close. Castellanos et al. also found that bees were completely ineffectual at transferring pollen of the extreme ornithophile Penstemon barbatus, whereas hummingbirds were supremely effective pollinators of this species, which is adapted to being pollinated by them.

The second sketchy point of our scenario lies in the unstudied "ecological changes" that involve a shift in the bee : bird ratio. Stebbins (1989) favored the idea that shifts to hummingbird pollination have often been preceded by a species colonizing and adapting to a novel habitat where bees are less active or birds are more active than in the ancestral habitat. He suggested that this might often happen in habitats where bees get a slow start in the morning because of fog and where hummingbirds have ample woods for nesting. Cruden (1972) also stressed poor weather as favoring dependence on birds. Otherwise, 

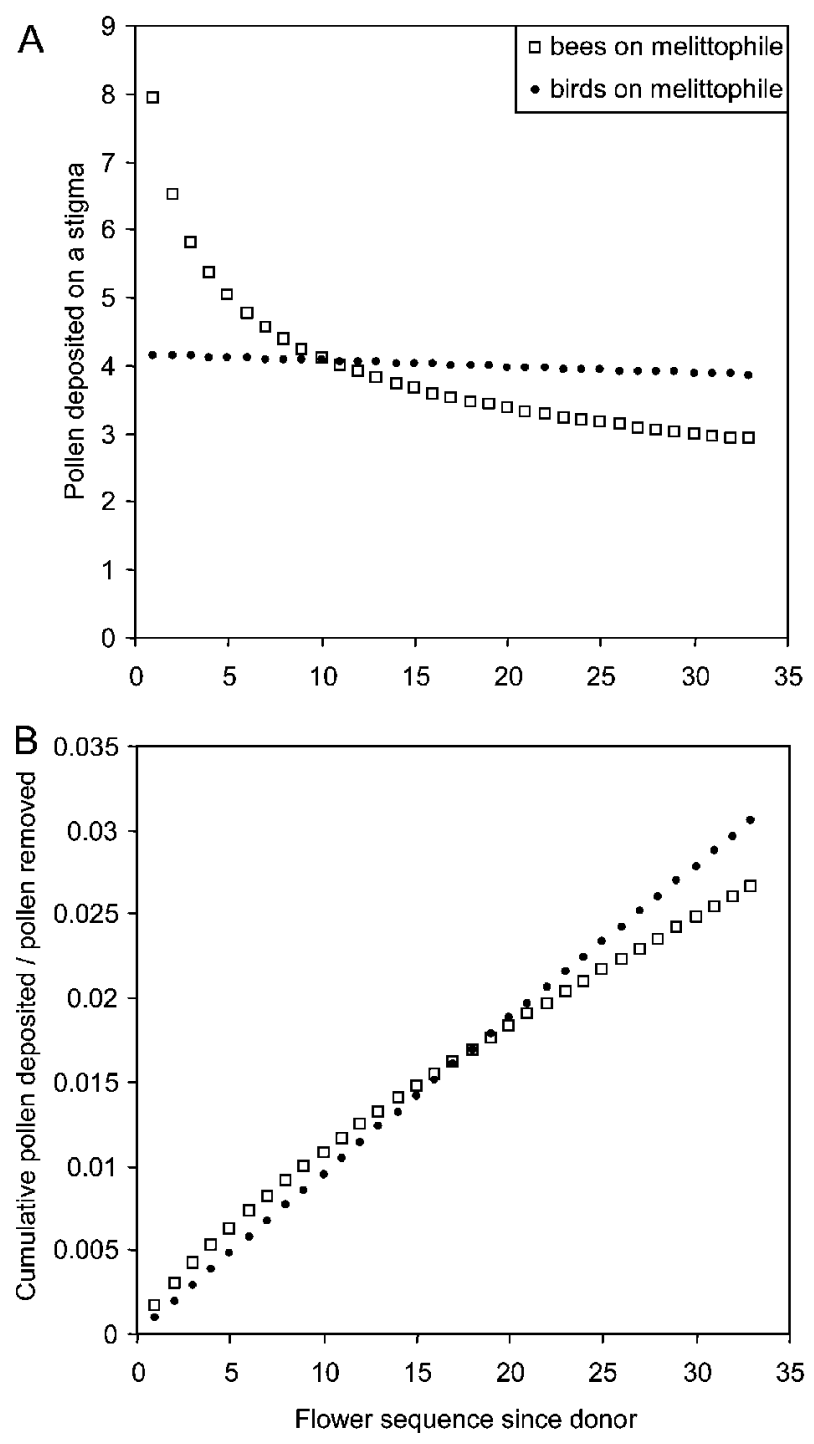

Fig. 2 Graphical depiction of why pollinators with flatter, longtailed pollen carryover curves are favored through male function over pollinators with steeper curves. $A$, Bees export more pollen to the first recipient stigmas but less to later recipient stigmas than birds. $B$, Cumulative pollen exported divided by pollen removed in a visit shows how male fitness is accrued; taking into account pollen carryover beyond ca. 20 recipient stigmas, birds appear to be better than bees. However, these curves are extrapolated from data on only the first 15 stigmas (Castellanos et al. 2003).

the causes of ecological changes in the bee : bird ratio have not been well discussed, and they are difficult to study experimentally. Hummingbirds will investigate melittophilous penstemons, so the critical obstacle keeping birds from moving on to a bee-pollinated plant lies in reward economics. The comparatively paltry nectar volumes of melittophilous species do not induce regular visitation by birds under normal circumstances, particularly when frequent visits by bees keep the flowers nearly empty (Williams and Thomson 1998; RodríguezGironés and Santamaría 2004). When Williams and Thomson continuously videotaped a plant of the melittophilous P. strictus for most of a day, thousands of bee visits were recorded but no bird visits; at the same site, however, hummingbirds do sometimes visit $P$. strictus flowers at daybreak, when nectar volumes may have accumulated overnight. Using a pipette, Jordan (2004) brought nectar offerings in the melittophilous Penstemon spectabilis up to the $5 \mu \mathrm{L}$ of $20 \%$ sugar found in the ornithophilous Penstemon centranthifolius, and hummingbirds immediately increased their visitation rate, despite the fact that the flowers were purple, had large lips, etc. This crude experiment suggests that hummingbird visitation quantity probably responds to nectar offerings directly. The study also suggests that something other than nectar offerings (flower color) may be important in determining visitation rates by bees, but unfortunately, at this study site, the bees involved were Ceratina, not industrious bees such as Bombus. After we have introduced the biology of a few other plant groups and brought up several other ideas, we will return to considerations of the ecology of shifts between pollination syndromes.

\section{Monkeyflowers: Ecology and Genetics}

The melittophilous Mimulus lewisii and the closely related ornithophilous Mimulus cardinalis (fig. 1C, 1D) have been studied by Bradshaw, Schemske, and colleagues (Bradshaw et al. 1995, 1999; Wilbert et al. 1997; Schemske and Bradshaw 1999; Bradshaw and Schemske 2003). The major articles from this team have mostly addressed the genetics of adaptation and the mechanisms of reproductive isolation, rather than the circumstances enabling the pollinator shift; nevertheless, the results have provocative implications for shifts. The team made crosses between the two species. Studying $\mathrm{F}_{2}$ hybrids and subsequent progeny arrays, they found that a modest number of major genes control some of the characters that most influence visitation rates. In other words, the pollination syndrome difference is largely attributable to genetic loci of fairly large effect. Moreover, they used the floral variation in an $\mathrm{F}_{2}$ progeny array to study the response of pollinators to multiple floral characters. By crossing the syndromes, they were able to recreate, in one place at one time, all the variation that must have been necessary to get from melittophily to ornithophily over evolutionary time. This allowed them to examine the different pollinators' reactions to all combinations of characters.

Hummingbird pollination has evidently arisen twice from bee pollination in Mimulus section Erythranthe (Beardsley et al. 2003). Thus, the direction is consistent with a seemingly widespread bias in favor of bee-to-bird transitions. In the species pair studied by Bradshaw and colleagues, M. cardinalis has evolved many ornithophilous traits compared with M. lewisii. Although sympatric speciation may have occurred, it is not implied by any data, nor have Bradshaw et al. pushed such a claim. For our purposes, we can envision that the two lineages might have first diverged in elevational preference, making them allopatric, with the nascent $M$. cardinalis living at lower elevations and $M$. lewisii living at higher elevations. Then later, we imagine, there was an adaptive shift in the lineage of M. cardinalis toward ornithophily. Eventually, the two species came to differ in nectar quantity, the extent of yellow carotenoid pigment, the amount of pinkish anthocyanin pigment, 
the orientation of the petal lobes, and the exsertion of anthers and stigmas. Each of these differences is partially attributable to a very few major loci (major loci being ones that account for $>25 \%$ of the variance among $\mathrm{F}_{2} \mathrm{~s}$ ), as well as probably some minor genes (Bradshaw et al. 1995, 1999). The extent of carotenoid pigmentation is controlled by a single genetic locus (yellow on upper petals [yup]; Hiesey et al. 1971). Other major quantitative trait loci (QTL) are associated with nectar offerings and petal orientation, characters that are prominent in constituting the difference in pollination syndrome.

The rates of visitation by bees and birds were studied in an array of $\mathrm{F}_{2}$ progeny set out at intermediate elevation (Schemske and Bradshaw 1999). As displayed in figure 3, multiple regression showed that anthocyanin concentration, carotenoid concentration, nectar production, and the projected area of the corolla each affected bee or bird visitation rates when the other three variables were statistically accounted for. Therefore, each trait makes a contribution to the difference in pollination syndrome and to which kind of animal visits an individual plant. Those $F_{2}$ individuals that resemble melittophilous $M$. lewisii receive many visits by bees and few visits by birds, while those $F_{2}$ individuals that resemble ornithophilous $M$. cardinalis receive many visits by birds and few by bees. Each of the $F_{2}$ individuals was genotyped, so Schemske and Bradshaw could quantify how well any particular QTL predicted the visitation rates of bees and birds. The genotype at the yир locus (governing whether the flowers are pink or orange) affected bee visitation such that orange individuals received only $20 \%$ of the bee visits received by pink individuals. This genetic locus had no significant effect on bird visitation. Other loci did, however; most notably, a QTL associated with nectar production cut bird visitation by $50 \%$. This nectar QTL had no significant effect on bee visitation.

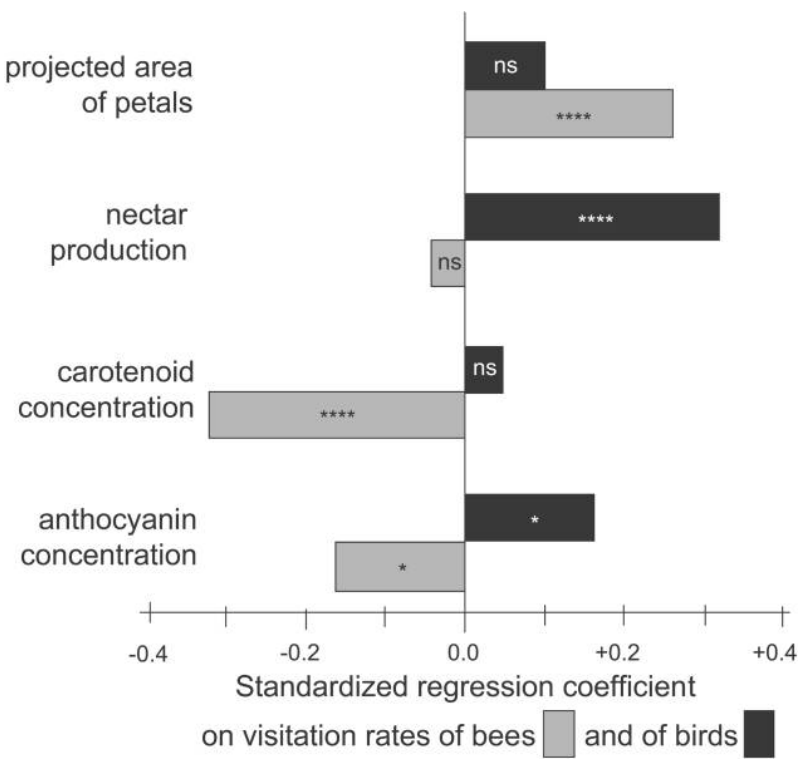

Fig. 3 Results of multiple regression of four floral traits on visitation rates by bees and by birds in an $\mathrm{F}_{2}$ array of monkeyflowers. Significance notes: ns, $P>0.05$; one asterisk, $P<0.05$; four asterisks, $P<0.0001$ (modified from Schemske and Bradshaw 1999).
The discovery of major genes differentiating syndromes is at least mildly unexpected. Ever since Fisher (1930), macromutations have often been dismissed as "hopeless monsters," so deviant that they ought to function poorly; also, genetic response to selection in a novel environment has been viewed as proceeding best when a character is affected by many additive genes of small effect. Such alleles are assumed to exist in any population and are available to be brought together to produce a phenotype more extreme than was previously present. Before Bradshaw et al. established the contrary, most evolutionists would have tended to attribute the syndrome differences in these two Mimulus to an indefinitely large number of loci of individually minor effect (see Orr and Coyne 1992; Coyne 1995), although perhaps Gottlieb (1984) would not have. Given Bradshaw et al.'s findings, one might imagine that a new mutation of large effect (such as $y u p$ ) might allow the population to "jump" to a state of adaptation to hummingbirds, and that until the new mutation of large effect arose, evolution might have been limited by insufficient variation to act upon.

Bradshaw and Schemske (2003) constructed genotypes that mimicked a new mutant of this sort; i.e., they produced plants with an allele that makes the flowers orange but that otherwise had nearly the genetic background of melittophilous $M$. lewisii. (The goal was to make this flower color locus countercorrelated with other syndrome-specific characters. Unfortunately, nectar offerings were dragged along, presumably because of a closely linked nectar locus, so the artificial "mutant phenotypes" were not exactly like real mutants, as mentioned in Bradshaw and Schemske 2003; see also Wilson et al. 2006.) On the basis of visits to these phenotypes, Bradshaw and Schemske calculated that if the bee : bird abundance ratio were to fall to around one-ninth of its value in contemporary field conditions, then a mutant with the yup allele would receive as many visits as a wild-type M. lewisii and would be mostly hummingbird pollinated, whereas the wild type would be mostly bee pollinated.

This calculation raises a question about pollinator shifts. Given that a single novel mutation like yup can by itself produce such drastic changes in the attendances of different pollinators, ought we to view such mutations as either necessary or sufficient causes of pollinator shifts? D. W. Schemske (personal communication) does not think so. He believes that ecological changes in pollinator visitation rates are necessary before the genetics of floral characters become important, following this scenario: (1) a change in the environment favored hummingbirds over bees, perhaps a drop in the abundance of bees; (2) any mutation that increased the frequency of hummingbird pollination was favored, regardless of its genetic basis; and (3) mutations of large effect were most likely to be fixed in the early stages of adaptation when the population was far from its phenotypic optimum.

Therefore, although our comparisons of melittophilous and ornithophilous relatives in the penstemon clade focus on the efficiency of pollen transfer by different pollinators, while Bradshaw and Schemske's comparisons of similarly related Mimulus species focus more on the genetic control of syndrome characters and the quantitative preferences of pollinators for those characters, the two research programs do not contradict one another. Both of them invoke externally driven ecological 
changes in visitation rates as the initiators of change. Both of them suggest particular phenomena that might facilitate the transition from one syndrome to another. In penstemons, general relationships of pollinator efficiency might provide a switch point and a ratchet mechanism that would foster transition to birds. In particular, one can envision that a small increase in hummingbird visitation could nudge a plant population over a pollen-transfer efficiency threshold. In Mimulus, alleles with large effects on floral phenotypes and visitation rates could provide the genetic variation necessary to allow selection to shift phenotypes beyond a visitation rate threshold, also given a decrease in the bee : bird ratio.

The Mimulus data are tantalizing but not decisive on the possibility that a shift in pollination syndrome might be made permanent through a new mutation of large effect. When Bradshaw and Schemske (2003) put yup into plants that otherwise were nearly M. lewisii, birds found them more attractive than wild-type M. lewisii and bees found them less attractive, but bees were still more frequent pollinators than birds; therefore, the data are hardly in favor of a shift being "initiated" only by a new mutation. Even without referring to this result, we share Schemske's skepticism about the possibility that a new mutation, without an extrinsic change in ecology, could have been selected to fixation, thereby concomitantly transforming a lineage adapted to bees into one adapted to birds. Instead, we prefer a scenario that starts with some extrinsic ecogeographic change that increases the relative frequency of visitation by birds, then a period of response to selection using existing or new genetic variation that eventually moves the lineage out of the melittophily vortex into the ornithophily vortex. The finding of alleles of largish effect in Mimulus raises the possibility that a new "macromutation" might have moved the lineage past the threshold, thereby committing it to ornithophily. Did the lineage leading up to $M$. cardinalis make permanent its escape from melittophily using preexisting genetic variation affecting nectar quantity, or using a new mutation affecting color, or using some other new mutation, or was it incrementally secured by several or many new mutations during a prolonged ecological perturbation caused by a low bee : bird ratio?

We are reluctant to believe that plants such as M. lewisii are unable to escape the melittophily vortex for lack of one macromutation that by itself allowed the ancestors of $M$. cardinalis to escape. If a single mutation such as yup were globally beneficial, we suppose it would have occurred already and swept throughout the species, destroying melittophily. Because $M$. lewisii and many other melittophiles seem stable as melittophiles, we assume they are trapped in their syndrome vortex. We assume that the various characters of $M$. lewisii keep hummingbirds from being important pollinators even in an individual that has a mutation that makes the flowers orange or in an individual with a mutation that increases nectar production by $25 \%$. Thus, we suppose that the shift between vortices was allowed because of special ecological circumstances and a series of loci being selectively substituted. In the case of Mimulus, the alleles involved were of fairly large effect at fairly few loci, and because of that, we assume they were new mutations. Our efficiency threshold scenario, however, is compatible with more conventional genetic assumptions. In Penstemon, we have not attempted QTL studies on syndrome characters, but we did study the variance among $\mathrm{F}_{2}$ offspring and among backcrosses of melittophilous Penstemon spectabilis and ornithophilous Penstemon centranthifolius (Jordan 2004). We studied morphological dimensions, nectar characteristics, and color spectra. In general, there was little or no deviation from additivity of parental character states, and there was no heightening of variance such as would be due to genetic segregation if a character differed because of one or two loci. The one possible exception was that color showed some suggestion of heightened variance, so perhaps major genes do play a role in pigment production.

When we envision the possible fixation of a single mutation that moves flowers past a threshold, a signaling-trait locus such as $y u p$ would not seem to be the most likely candidate. Signaling is important, because pollinators use signals to distinguish one phenotype from another. On that basis, one might expect that there is an especially steep selection gradient for a signaling trait, but there is a catch. Although pollinators do frequently respond to color signals, their preferences are generally developed through associative learning of colors associated with floral rewards. Preferences for the colors that are classically associated with syndromes are not always present and can be overridden by reward economics (Waser et al. 1996). For a few examples, bumblebees in northern Wisconsin prefer orange Hieracium aurantiacum to yellow Hieracium florentinum in mixed stands (Thomson 1978); hummingbirds in Colorado will seldom visit red Penstemon barbatus if brown Scrophularia lanceolata is blooming nearby (J. D. Thomson, unpublished observations); and in the lab, naive Bombus impatiens are more likely to prefer red artificial flowers than blue ones (Gegear and Burns 2007). In Mimulus, we would not expect hummingbirds to consistently restrict their visits to orange phenotypes or bees to pink, unless first there were economic advantages for them to do so (also the opinion of $\mathrm{H}$. Bradshaw [personal communication]).

For monkeyflowers, we envision a scenario in which ecological circumstances interact with new mutations to produce a shift. Imagine that the incipient $M$. cardinalis, still pink, is living at a site where increased nectar production is favored, perhaps because the plants are growing at warmer low elevation where the cost of producing nectar is diminished. Both hummingbirds and bees come to be regular visitors. As in our hypotheses regarding quality, we will further suggest that hummingbirds are less wasteful at delivering a plant's pollen to stigmas. Selection would favor increases in nectar production, and hummingbird pollination would become further established by selection favoring anther/stigma exsertion, narrowing of the floral tube, reflexing the petal lobes, and other characters that increased the efficiency of placing pollen on the foreheads of birds and removing it from those foreheads. The yup mutation could have arisen and spread during this stage of consolidation. In short, although yup has potent effects on pollination and may have promoted the shift in Mimulus after it was under way, it is not likely to have driven the shift on its own. While we are speculating freely, we note that plants of section Erythranthe live in wet seeps, so that increased nectar production in lower, warmer habitats might not entail meaningful water costs. It would be interesting to have some data on the pollen-transfer efficiency of bees and birds visiting M. cardinalis and M. lewisii and on the cost of nectar at high and low elevations. 


\section{Directionality: Lessons from Three Genera}

Although phylogenetic studies cannot yet support a full meta-analysis of the many genera that contain melittophiles and ornithophiles, there seem to be many more shifts from bee pollination to hummingbird pollination than the other way around (Faegri and van der Pijl 1979; Wilson et al. 2007). In our discussion of penstemons, we suggested that this is because hummingbirds have the capacity to become more efficient at transferring pollen than bees. However, there may well be other factors involved, as indicated by work on Ipomoea, Costus, and Aquilegia.

Morning glories. Zufall and Rausher (2004) studied the floral pigments of morning glories (fig. $1 E, 1 F$ ). Comparing the red ornithophilous Ipomoea quamoclit to the blue-purple melittophilous Ipomoea purpurea, they concluded that a reversal from red to blue would be very difficult. The biochemical pathway has changed in at least two and probably three ways (fig. 4). (1) In I. quamoclit, F3'H, the enzyme that leads to blue cyaniden, has been downregulated almost out of existence. This prevents the pathway from moving anthocyanins toward blue cyaniden. (2) The next enzyme in the pathway, DFR, has evolved greater specificity for dihydrokaempferol, the reactant that would have been acted on by $\mathrm{F}^{\prime} \mathrm{H}$, and a lessened ability to catalyze the product of $\mathrm{F}^{\prime} \mathrm{H}$, dihydroquercetin; thus, this second enzyme now moves anthocyanins toward red pelargonidin. (3) The downregulated $f 3^{\prime} b$ gene is apparently accumulating structural mutations, so it would not work properly even if it were turned back on. Overall, it seems very improbable that "lucky" mutations could reverse all these
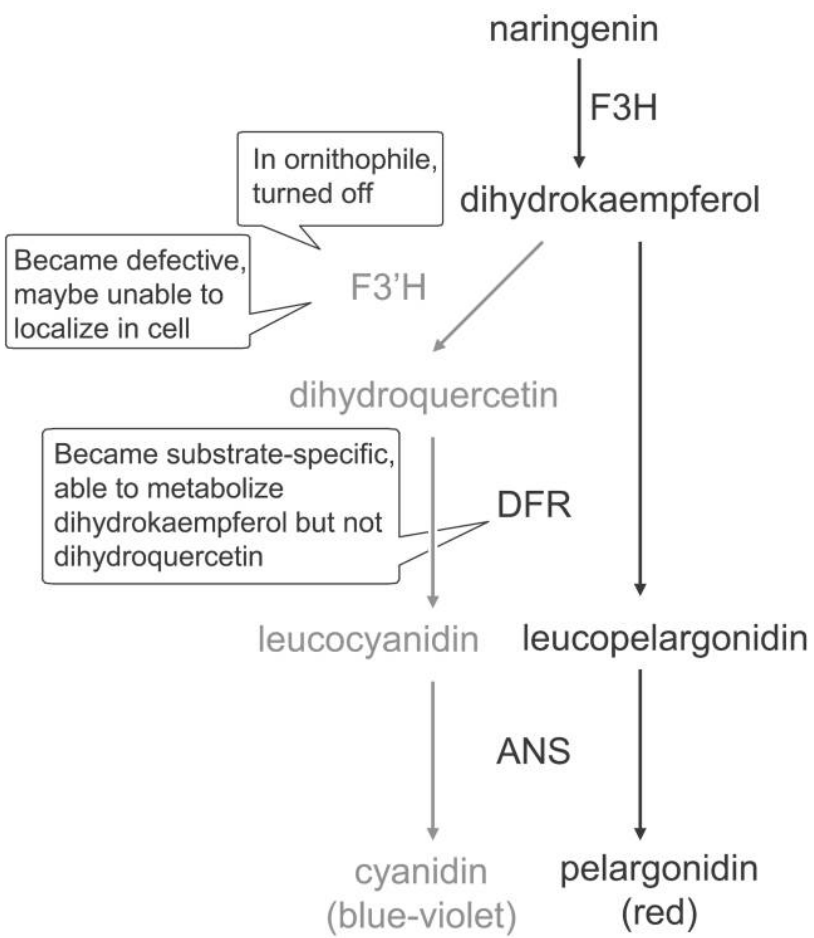

Fig. 4 Three modifications to the anthocyanin pathway in the redflowered Ipomoea quamoclit. Parts of the pathway that have been deactivated are in gray (modified from Zufall and Rausher 2004). changes simultaneously or recruit other copies of the genes while reversing other changes. Evolutionary shifts from bluepurple to red may be quite easy, but then there may be no going back. To the extent that floral colors dictate pollination, this mechanism may produce a directional bias that favors beeto-bird shifts.

The findings of Zufall and Rausher (2004) for Ipomoea are not directly relevant to the characters studied in monkeyflowers. First, Bradshaw and Schemske have focused on the effects on pollinator visitation of carotenoids more than anthocyanins. Second, in monkeyflowers the crucial difference in carotenoids is whether the yellow patch is restricted to the throat of the flower or spread across the whole upper petal. Therefore, it is not a matter of turning off the pathway completely through a loss-of-function mutation. Third, there is a difference in anthocyanins, but it depends as much on the amount of anthocyanins as on which anthocyanin is abundant in the petals (Wilbert et al. 1997). The Zufall and Rausher conclusions may apply better to penstemons, where red flower colors appear to have evolved by changing the kinds of anthocyanins (Rausher 2008).

In Ipomoea, color may be particularly important in pollinator shifts, but as we have argued previously, differences in nectar rewards are likely to be important too. Ipomoea species variously appeal to bees, hummingbirds, and hawk moths, but their conformity to multicharacter syndromes may be less coherent than in monkeyflowers and penstemons. In six Argentine species of Ipomoea, differences in nectar seem to be explained more by differences in flower size than by the type of pollinator (Galetto and Bernardello 2004). The bird-pollinated species produce more dilute nectar less gradually, but a largeflowered sphingophile produces the most nectar, and several of the bee-pollinated species have sucrose-rich nectar. Morning glory flowers are radially symmetric, which may provide less opportunity for conformity to multicharacter syndromes. In addition, the center of radiation for morning glories is tropical, where there is much more variety in the hummingbird fauna than in the temperate montane biomes we are more familiar with. Additional information on the phylogeny (Miller et al. 2004) will be especially informative when the pollination biology of the species included in the phylogeny has been studied.

Costus. There are ca. 51 species of Neotropical Costus (fig. $1 G, 1 H)$. They are pollinated either by euglossine orchid bees or by hummingbirds, and pollination syndrome characters are reliable predictors of which kind of animal actually visits the flowers (Kay and Schemske 2003). The New World clade is nested within Old World Costus, and molecular clock data indicate a 1.5-7.1-million-year-old radiation. Hummingbird pollination is inferred to have arisen about seven times, with no compelling case for any reversals (Kay et al. 2005). Again, ornithophily appears to be a one-way attractor. Costus arrived in the Neotropics after hummingbirds were established. It already had large flowers with abundant nectar. It adapted to orchid bees first, and in its subsequent diversification, a high proportion of the euglossine-pollinated lineages have spun off hummingbird-pollinated lineages. Costus plants are typically very widely spaced and thus are appropriately pollinated by orchid bees and hummingbirds, both of which remember where resources are and forage over long distances. This constraint 
may prevent Costus from switching over to smaller pollinators. The pollination syndromes in Costus are based more on signaling than on rewards. Nectar offerings are high in both orchid bee-pollinated species and hummingbird-pollinated species.

Within a pollination syndrome, Costus species are maintained by barriers such as where pollen is placed on the body of the pollinator. Kay (2006) reported on the reproductive isolating barriers between two closely related species, Costus pulverulentus and Costus scaber. Postzygotic barriers are probably fairly weak, and there are only modest barriers because of geography, microhabitat, and phenology. Both these flower species mostly use the long-tailed hermit hummingbird, but the anthers and stigma of C. pulverulentus are exserted, so that pollen is carried on the bird's forehead, whereas in C. scaber the anthers and stigma are more included in the floral tube, so that pollen is carried on the beak. This produces reproductive isolating barriers in both directions, though more so for C. scaber pollen donors by C. pulverulentus recipients than vice versa. There are also strong barriers to interbreeding at the stage of pollen germination and growth down the style, but we find Kay's results for pollen movement noteworthy. We would expect that more pollen would be lost from beaks than from feathered foreheads (Castellanos et al. 2003), which would lead us to expect that male-male competition might select for more exserted sex organs in C. scaber. Perhaps our intuition about pollen wasting is wrong; alternatively, the greater wastage entailed by beak pollination could be offset by improved precision of pollen placement. Details of pollen transfer by the euglossine bees would be valuable.

Columbines. There are 25 North American species of Aquilegia (fig. 1I, 1J). Whittall and Hodges (2007) studied them all, revealing that much of floral evolution occurred through pollinator shifts. An ordination based on floral traits displays three distinct pollination syndromes. The melittophilous species are blue-purple with spurs of ca. $1 \mathrm{~cm}$. The ornithophiles are scarlet with yellow and have slightly longer, often straighter spurs. The sphingophiles are yellow or pale violet, with much longer spurs and upright flowers. Melittophily is the ancestral condition, from which ornithophily arose twice. Then sphingophily arose from ornithophily five times. This directionality is statistically significant, and the shifts are significantly associated with increased spur length, which occurred mainly in one of the two lineages that emerged from points of cladogenesis where there was a pollinator shift. Sphingophily never arose directly from melittophily, and no Eurasian columbines have gone over to hawk moth pollination.

Ornithophilous and sphingophilous columbines are still visited and pollinated by bees, even though the nectar is inaccessible to them unless they rob from the spurs, which effects no pollination. Pollen can be transferred by bees when they collect pollen, and we predict that they remove large quantities of pollen per visit, of which a relatively low proportion is moved to stigmas compared with amounts transferred by hummingbirds and hawk moths. In some populations in some years, however, the "legitimate" pollinators are so rare that attracting bees is probably adaptive, averaged over evolutionary time and space (Miller 1978, 1981).

Intriguingly, the melittophilous columbines seem to present their pollen gradually as waves of anthers mature, whereas the ornithophiles and sphingophiles seem to dehisce anthers in a less orderly manner (J. Whittall, personal communication). If verified, this would be consistent with our finding that melittophilous penstemons have more metered pollen presentation than related ornithophiles (Castellanos et al. 2006).

Much research on pollinator shifts in columbines has focused on the comparison of ornithophiles to sphingophiles (Fulton and Hodges 1999), which we will not abstract here. We suggest, however, that Aquilegia differs from Penstemon and the other genera we have mentioned in having many anthers, which might predispose it to sphingophily. We can further extend speculation along these lines to explain the lack of shifts in Penstemon and Mimulus to other syndromes. If we are right, then perhaps there are no shifts to hawk moth pollination in these genera because hawk moths (it may be presumed) remove very little pollen in a visit to a flower with four anthers. Other explanations of the same general structure but with differing details could also be offered. It seems likely that the nectar spurs of columbines can easily respond to selection favoring greater length without compromising their simple function. This may not be true for penstemons where nectar is secreted by the stamens near their base and whose normal floral function seems to depend on stiff stamens and styles being positioned for nototribic pollen transfer. If selection pulled penstemon corolla tubes out to the length and thinness required to enforce sphingophily, the filaments and style might become so attenuated and floppy as to lower the precision with which they transfer pollen via birds or moths.

\section{Multiple Traits}

The concept of a few pollination syndrome vortices of different strengths and sizes encompasses the three elements of transitions that we set out to explain: (1) clusters of phenotypically similar plants that have converged on one of two alternative states, (2) occasional vortex-escaping transitions from one state to the other, and (3) biased directionality of those transitions. But the abstract notion of vortices needs to be fleshed out. What factors give a vortex its distinctive character?

One important factor, recognized by Faegri and van der Pijl (1979), must lie in the cognitive characteristics of the pollinator. They wrote, "In reality the 'why' of pollination ecology is largely animal psychology" (p. 5). It seems likely that the visual system of the pollinator and some amount of sensory drive (sensu Endler 1992) underlie the strong correlation of flower color with pollination mode, although it is very risky to ascribe observed color preferences to innate predispositions of pollinators (Chittka and Waser 1997). Differences in the odors that attract various animals add another dimension to differences in pollination syndrome. Other important cognitive factors would include how pollinators sample, perceive, and react to nectar or pollen rewards. For example, bumblebees strongly prefer smaller volumes of more concentrated nectar to energetically equivalent, larger volumes of more dilute nectar (Cnaani et al. 2006). Although we lack parallel data for hummingbirds, this behavioral predisposition of bees may open an opportunity for plants to discourage those bees (by providing copious but dilute nectar) without discouraging birds to the same degree. This example reinforces the necessity to consider the question raised by Faegri and van der Pijl 
(1979) and stressed by Castellanos et al. (2004): When a floral character changes during a pollinator transition, does the change serve to improve pollination service by the new pollinator or to deter wasteful visits by the old one? It is not always easy to tell, but before we can make a meaningful interpretation of the character as a response to an animal's cognitive properties, we must answer the question of which animal we are talking about.

In addition to the cognitive properties of different pollinators, floral phenotypes should also respond adaptively to the principal pollinator's shape, size, and characteristic posture. Obviously, selection will tend to place anthers and stigmas so that pollen transfer is achieved, but again there are subtleties. For example, the exserted sex organs and the narrow corolla tube of ornithophilous penstemons may work well only in concert (Castellanos et al. 2004). If the corolla tube is narrow, birds must approach straight along its axis, and exserted sex organs on the flower's midline will contact the forehead. If the organs are exserted but the corolla remains widely flared, birds can approach laterally and may not pick up or deposit pollen. These considerations suggest that there may be a characteristic order in which character changes are introduced during a shift between syndromes (Wilson et al. 2006). Some may be prerequisites for others. We suspect that reward and signaling characters are likely to change first because they relate directly to enforcing the change from old pollinator to new. Changes in morphology and pollen presentation would tend to follow as a part of improving the effectiveness of the new pollinator.

Explanations of specialization based on distinct syndromes (as opposed to wandering) have typically assumed the existence of some kind of trade-off in which being adapted to one kind of pollinator (bees) makes flowers maladapted to another kind of pollinator (birds; see the many citations in Aigner 2006; Muchhala 2006). A flower cannot be in two vortices, or else the vortices would not be distinct. Previously, we drew attention to heterogeneities in the slopes of selection gradients (Wilson and Thomson 1996). For example, pollinator-driven divergence could result if shorter stamens and styles work well with bees whereas longer stamens and styles work well with birds. Such differences in the direction of the slopes have eluded empirical study, although they seem plausible enough when we observe the end products of divergence. Aigner (2001, 2004,2006 ) has carefully discussed the trade-off assumption, studying natural variation, doing experiments with manipulated phenotypes, and using graphical models. He points to a situation in which trade-offs are not manifest; instead, a flower works well with one kind of pollinator (bees) regardless of phenotype, but with another kind of pollinator (birds), the flower has a fitness-on-phenotype function that is narrow and peaked. When this is the case, the flower ought to master the use of birds, acquiring long stamens and styles, while still using bees. The flowers will become more generalized, at least in the sense of lengthening their list of effective pollinators. In Schemske and Bradshaw's (1999) study (fig. 3), when one character at a time was looked at, only anthocyanin concentration showed a significant fitness trade-off: bees preferred more and birds preferred less anthocyanin. Other single characters were preferred by bees or by birds, with the other kind of animal being indifferent. Aigner was cautious about even recognizing syndromes as being vortices because his attention was focused on single characters. Our view, focusing on pollinator quality, is that bees can become conditional parasites. This allows for another kind of trade-off. Once a population is past the threshold, any character that discourages bees is selected for, as is any character that improves the pollen transfer effectiveness of birds. The stability of the bird vortex becomes multivariate as more characters are progressively recruited.

The stability of the bee vortex derives from its evolutionary history: multiple characters, which were presumably recruited sequentially over evolutionary time, function together in an integrated fashion. Indeed, it is the multivariate nature of the syndrome that makes the syndrome a vortex-that coupled with the social way in which flowers work as a team (see Wilson et al. 2006). In a large patch of a melittophilous penstemon, an individual that makes unusually dilute copious nectar is unlikely to attract hummingbirds, and even if a hummingbird did visit, its potential effectiveness as a pollinator would probably not be realized. The mutant individual's flower color, landing platform, vestibule size, and anther and stigma exsertion would all be suboptimal for hummingbird pollination, and all the other individuals in the patch would be more attractive to bees than to hummingbirds. Thus, the status quo perpetuates itself, effecting what might be called multiple-trait centripetal stasis. The adaptive stable state of melittophily ensures that most of the visits are by bees, and that, in turn, ensures that most of the pollination is by bees. In addition, the geometry of the flower is already adapted to bees, so even if a mutation does attract more birds quantitatively, their qualitative superiority is unlikely to be fully manifest. Therefore, selection tends to be purifying and to disfavor deviations from the quantitative norm, even when another pollinator would have the potential to be qualitatively better on a per-visit basis (see similar argument by Kirkpatrick and Barton [1997] for how adaptation at the center of a range prevents adaptation at the edge of a species' range).

Functional interactions among syndrome characters may channel and constrain evolution (Armbruster 1990; Wilson et al. 2007). Syndromes and other such strategic concepts are fundamentally about how characters work well together (Fenster et al. 2004), but there has been almost no empirical study of multiple-trait synergism of the characters involved in bee-tobird transitions. In lieu of such work, we review two empirical studies on individual characters that are important in the bee and bird pollination syndromes and whose explanation involves multiple traits, some affecting quality and some affecting quantity.

Campions. In eastern North America (where there is only one species of hummingbird, the ruby-throated hummingbird), Silene virginica conforms to the hummingbird syndrome (fig. $1 K, 1 L)$. Close relatives are pollinated by nocturnal moths and by diurnal bees and Lepidoptera (Fenster et al. 2006). Fenster and Dudash (2001) caged plants with mesh that kept out birds but allowed bees to visit. They found that the caged plants produced fewer seeds each year for several years at both a woodland site and a meadow site. Therefore, the plants benefited from the pollinators that syndrome characters suggest they are adapted to. The degree of benefit varied with year and site. However, the plants may well have also benefited from "illegitimate" pollinators, particularly when and where 
hummingbirds were scarce. Subsequently, Fenster et al. (2006) artificially decoupled petal size and corolla tube width from nectar offerings and found that hummingbirds prefer flowers with larger petals, but they do not generally prefer narrower tubes. This suggests that the narrowness of the floral tubes in $S$. virginica is an adaptation not to improve the quantity of hummingbird visits but to improve the quality of bird visits or to exclude pollinators of inferior quality.

Sages. Many of the features that make the penstemons interesting are mirrored among the sages, and Salvia could provide even further scope for comparative studies because it includes both passerine and hummingbird ornithophiles. In addition to classic work reviewed by Faegri and van der Pijl (1979, pp. 147-148), much phylogenetic and functional research is under way, and we expect new insights about pollinator transitions to emerge. Wester and Claßen-Bockhoff (2006) have studied pollen presentation. Many melittophilous Salvia have a well-known "staminal lever" mechanism that has generally been interpreted as a device for the precise nototribic placement of pollen on bees. Typically, the anthers are held against the roof of the flower until a bee enters deeply to probe for nectar, at which point the anthers are indirectly pushed down to touch the bee's notum. This mechanism is frequently inactivated in ornithophilous species (fig. 5); in a study of anther function in the hummingbird-pollinated Salvia haenkei, Wester and Claßen-Bockhoff (2006, p. 142) mention that at least 50 similar ornithophilous species show "reduced or stiffened staminal levers." Although phylogenetic information is not presented, it seems likely that some of these represent independent convergence toward bird pollination, causing deactivation of the lever mechanism. Although these authors are inclined to view the loss of levering as a side effect of elongation and narrowing of the corolla tube to better fit birds or exclude bees, an alternative explanation is possible (such as the pollen-dosing explanation by Castellanos et al. [2006]). Perhaps staminal levering is advantageous in bee flowers because it achieves restricted pollen dosing in addition to precise placement. Then, as in penstemons and perhaps in columbines, adaptation to birds relaxes selection for dosing. Although we

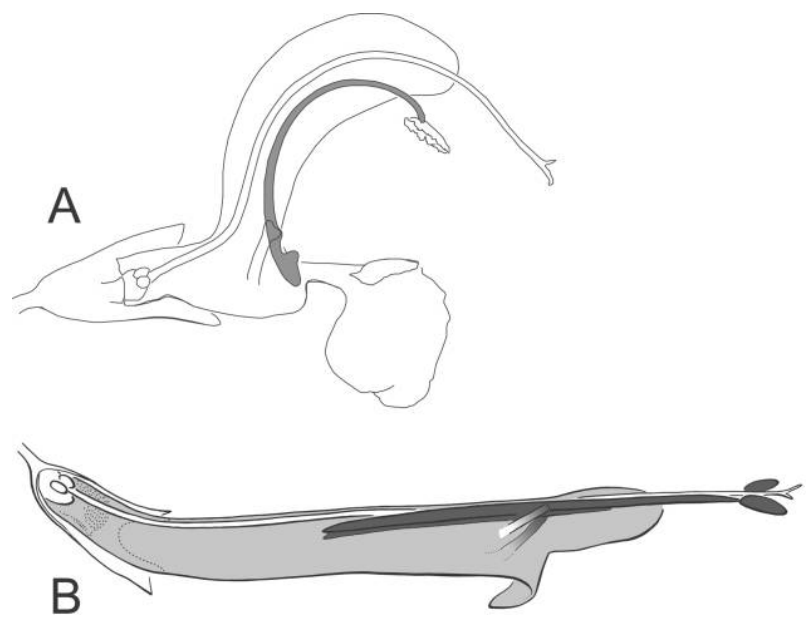

Fig. 5 Loss of the staminal lever in a hummingbird-pollinated sage. A, Melittophilous Salvia pratensis. B, Ornithophilous Salvia haenkei (artist: D. Franke). need more phylogenetic information to judge the strength of the correlation between lever loss and ornithophily, and more information about pollen transfer to judge the applicability of the pollen-dosing hypothesis, the putative correlation is highly suggestive of some link between pollen transfer and the transition to ornithophily.

\section{Broadening the Applicability of Our Ideas}

The salient challenge for explaining bee-to-bird pollination shifts that are replicated more or less faithfully across different genera is to explain what factors destabilize established plantpollinator relationships. One would expect established relationships to continue under purifying selection unless some special circumstance turns wandering evolution to revolution. A sufficient but easily rejected possibility is that bees simply disappeared from large geographic regions for large spans of evolutionary time. Some melittophilous species would then become extinct, others would become autogamous, and some might adapt to other pollinators that would visit them without immediate evolution. We consider such a regional bee extirpation to be unbelievable; a good explanation must explain how bee pollination can become destabilized while bees remain a component of the regional community. We can envision sustained depressions of numbers or even transient disappearances but not a sustained wholesale disappearance of bee pollinators. Perhaps more palatable is to invoke a depression in bee visitation during certain times of day in certain habitats (Stebbins 1989). By this view, a plant lineage would first evolve to grow in a different habitat than its progenitors, and this would impose on it a changed pollinator regime that would then disrupt the status quo (Sargent and Vamosi 2008).

In what other ways could the usual neglect by hummingbirds of a melittophilous flower be disrupted? Changes in plant community composition can upset prevailing patterns of floral use. Faegri and van der Pijl (1979, p. 51) recount that "a breakdown of blossom constancy .... is easily seen when, for example, Trifolium pratense comes into flower: owing to its greater nectar production it suddenly attracts all long-tongued bumblebees that are able to reach the nectar, causing an immediate neglect of other bee blossoms." A novel invasion of such a super-rich species could disrupt traditional allegiances; if bees were to abandon a penstemon for a clover, for example, the penstemon might in turn begin receiving more attention from birds. Alternatively, an important ornithophile might disappear from a local community, forcing birds to forage on a melittophilous species that they would normally disdain. Substantial spatiotemporal variation in bee : bird ratios has been observed in the ornithophilous Ipomopsis aggregata (Price et al. 2005). Abandonment of a host plant by pollinators does not require the disappearance of the plant itself, only the reward. For example, in Irwin, Colorado, in 2002, a drought caused I. aggregata to cease producing nectar, which in turn increased hummingbird attendance at artificial feeders (J. D. Thomson, unpublished data).

These possible changes in situation seem plausible in the short term, but for the situation to be sustained over evolutionary time would be much rarer (as well as practically impossible to study). An interesting moment in evolutionary time may occur at the end of a glacial period when range-extending 
hummingbirds first reach communities that lack ornithophilous plants. In most contemporary communities in which birds are common, they can afford to bypass low-nectar melittophilous species in favor of high-nectar species adapted to birds. If ornithophiles have not yet evolved or migrated into communities, however, newly arrived birds will need to choose the best foraging options from the existing flora, which will probably be dominated by melittophiles. The best species available may be those that, like some penstemons, replenish nectar rapidly after draining (Cruden et al. 1983; Castellanos et al. 2002); such characteristics may predispose certain genera to shifts toward ornithophily. The first wave of birds may provide a unique opportunity for melittophilous species to recruit bird visitors and thereby cross the efficiency threshold. After ornithophiles that offer high volumes of nectar have become abundant in a community, such transitions may become much harder.

We offer these speculations about ecological changes not because we think we can know which of these or others allowed for bee-to-bird shifts but to illustrate the role of ecological changes. That such moderately prolonged local rare extrinsic changes set the stage for pollinator shifts is a general concept. It is analogous to the familiar scenario for allopatric speciation in which a peripheral, isolated population is first extrinsically isolated by geography and then selection directly or indirectly changes its reproductive system so that it is intrinsically isolated (Futuyma 1998, p. 482). Here, we are not necessarily dealing with the origin of reproductive isolating mechanisms (which may come before a shift in syndromes or during a shift in syndromes), but the same general idea applies: shifts may occur in isolated lineages that experience a novel selective regime.

Although we view ecological changes as the most likely initiators of pollinator shifts, a very special mutation or coincidence of special mutations could in principle cause a shift. It would have to be a mutation that caused a drastic change in one character (e.g., nectar production) or just the right pleiotropic changes in multiple characters (e.g., a change from pink to red coupled with a change from low to high nectar production). Aigner (2006) seems to suggest that such pleiotropic variation could be responsible for differences in specialization on bees versus on birds. A pleiotropic mutation of just the right sort provides a multicharacter way to obviate the need for single-character trade-offs. Evidence of such a pleiotropic mutation would be hard to find. If such a genetic correlation were found between two established species (a melittophile and an ornithophile), it would not necessarily prove that the two character changes arose simultaneously through the same pleiotropic mutation; the mutation for copious nectar production could have arisen first and swept through the population, and then the mutation for red could have arisen in a closely linked gene and swept through the population, leaving no gene copies that had the first but not the second mutation. We remain skeptical of shifts without changes in ecology, simply because the selective sweep would spread throughout the species and not leave behind a melittophilous ancestral form for us to observe. The reason for erecting all our elaborate explanations is to explain the multifaceted nature of syndromes.

Nevertheless, Bradshaw and Schemske's work still suggests that large mutations may promote shifts, moving lineages past the threshold beyond which an evolutionary shift no longer requires special ecology. Because key syndrome characters in
Mimulus are indeed controlled by major genes, it is likely that the pollinator shift in Mimulus involved "special genetics," i.e., large novel mutations rather than standing variation. It is certainly conceivable that similar effects influence transitions in other clades, too. In our minds, however, mutations of large effect are probably not essential for pollinator transitions. Normal variation drawn from many genes of small effect throughout the genome can be recombined through sexual reproduction and selection to cause very large changes in quantitative traits (Futuyma 1998, pp. 27, 283-285; Barton and Partridge 2000; see also Mitchell and Shaw 1993 for traits in Penstemon). For the simple biochemical pathways involved in pigment production, perhaps a few loci will play prominent roles, but for many other traits, there is no reason to think that new mutations are needed for a shift between pollination syndromes, that is, to get the lineage past the threshold. Notice that, regardless of the genetic basis for character variation, a pollinator shift still takes many generations and in this sense is always genetics limited (Wilson et al. 2006). Whether it proceeds by the fixation of new macromutations or by bringing together numerous alleles of small effect, the substitution of alleles by selection takes time.

The phenomenon we have focused on-bee-to-bird shifts of distinct syndromes-does invoke some biology specific to bees and birds. Most notably, bees feed pollen to their brood and prefer concentrated nectar, whereas birds have no interest in pollen and can better transport and process copious amounts of dilute nectar. Schemske and Horvitz (1984) made pollination biologists appreciate differences in quality of pollination and how those differences in quality are important in understanding floral diversification (Herrera 1987; Wilson and Thomson 1996). We suggest that in the absence of quality differences-i.e., if all kinds of pollinators were to transfer the same fraction of the pollen they removed-the phenomenon of pollination syndromes would be greatly diminished. Syndromes would have no basis in effect, only in the trade-offs that cause differences in quantity of pollinator visits. Such "syndromes" would be simpler than the multicharacter vortices that we have been postulating.

Basically, the broader applicability of our ideas to pollination systems depends on the extent to which syndromes exist and are distinct. When diversity is syndromelike, the factors we have considered would seem to apply. One would just have to know how the two types of pollinators differ in their responses to various attractants and in their potential pollentransfer efficiencies. How do long-tongued flies differ in psychology and in pollen-transfer effectiveness from bees?

Although we have tried to discuss several aspects of evolutionary transitions between well-defined pollination syndromes, our principal thesis is that such transitions involve thresholds. Something must propel a plant lineage out of one pollinator's sphere of influence and into another's, and we think that pollentransfer efficiencies may well determine where the critical thresholds lie. Thinking about pollinator efficiencies further suggests reasons why shifts ought to be easier in one direction than in the reverse, why shifts from syndrome $X$ to $Y$ should be easier than from $X$ to $Z$, and how some lineages can be predisposed to subsequently shifting from $Y$ to $Z$. Such shifts should generally be hard but will be easiest when the efficiency of an "illegitimate" pollinator is fortuitously quite 
good and can be improved on by some simple changes in floral dimensions. Of course, these ideas have much less force in explaining diversifications based on adaptive wandering within one broad flat vortex (generalized entomophily) or even being drawn from a generalized relationship with many pollinators into a specialized relationship with a few. Threshold mechanisms become essential only when escape from one vortex must precede entry into another one.

Does our explanatory framework have any applicability outside pollination biology? There may well be parallel, vortexlike phenomena in other transitions discussed in this special issue, such as shifts between outcrossing and selfing, cosexuality and dioecy, or animal pollination and wind pollination. If so, the study of those transitions would benefit from explicit consideration of how the alternative states are generally stabilized, what the defining characters are, and how those characters interact with ecological circumstances to drive lineages over thresholds. But these other types of evolutionary transitions also require other considerations. Many of them would change the genetic system much more radically than would a pollinator shift from bees to birds. The change in the genetic system, for example, a large increase in homozygosity, could itself enter into the evolutionary dynamics of the transition (see Wright et al. 2008). We have not considered genetic rami- fications of this sort because we expect them to be minor in pollinator shifts. For similar reasons, we have also ignored reallocation of resources from one function to another, although such reallocation may be central to other transitions such as sexual systems (see Sakai et al. 1997). Although it is possible that increasing nectar output associated with ornithophily involves a reallocation of energy or of water from some other function, we judged such effects to be small enough to be excluded from our main arguments. Thus, our narrow focus led us to ignore some phenomena that might play key roles in other transitions. However, the elements that we chose to develop at length may indeed have analogs in other transitions.

\section{Acknowledgments}

We thank Toby Bradshaw, Doug Schemske, Chris Caruso, Kathleen Kay, Scott Hodges, Mark Rausher, Petra Wester, Justen Whittall, and two anonymous reviewers for data, ideas, corrections, and unpublished work. Maria Clara Castellanos made invaluable contributions to our understanding of penstemons. The penstemon work was supported by a National Science Foundation grant to J. D. Thomson, P. Wilson, W. S. Armbruster, and A. Wolfe, plus Natural Sciences and Engineering Research Council funding to J. D. Thomson.

\section{Literature Cited}

Aigner PA 2001 Optimality modeling and fitness trade-offs: when should plants become pollinator specialists? Oikos 95:177-184.

2004 Floral specialization without trade-offs: optimal corolla flare in contrasting pollination environments. Ecology 85:2560-2569.

2006 The evolution of specialized floral phenotypes in a fine-grained pollination environment. Pages 23-46 in NM Waser, J Ollerton, eds. Plant-pollinator interactions from specialization to generalization. University of Chicago Press, Chicago.

Armbruster WS 1990 Estimating and testing the shapes of adaptive surfaces: the morphology and pollination of Dalechampia blossoms. Am Nat 135:14-31.

Armbruster WS, CB Fenster, MR Dudash 2000 Pollination "principles" revisited: specialization, pollination syndromes, and the evolution of flowers. Det Nor Vidensk Acad I Mat Natur Lk Skr Ny Ser 39:179-200.

Baker HG 1963 Evolutionary mechanisms in pollination biology. Science 139:877-883.

Barton N, L Partridge 2000 Limits to natural selection. BioEssays 22: 1075-1084.

Beardsley PM, A Yen, RG Olmstead 2003 AFLP phylogeny of Mimulus section Erythranthe and the evolution of hummingbird pollination. Evolution 57:1397-1410.

Beisner BE, DT Haydon, K Cuddington 2003 Alternative stable states in ecology. Front Ecol Environ 1:376-382.

Bradshaw HD, KG Otto, BE Frewen, JK McKay, DW Schemske 1999 Quantitative trait loci affecting differences in floral morphology between two species of monkeyflower (Mimulus). Genetics 149: 367-382.

Bradshaw HD, DW Schemske 2003 Allele substitution at a flower colour locus produces a pollinator shift in monkeyflowers. Nature 426:176-178.

Bradshaw HD, SM Wilbert, KG Otto, DW Schemske 1995 Genetic mapping of floral traits associated with reproductive isolation in monkeyflowers (Mimulus). Nature 376:762-765.

Castellanos MC, P Wilson, S Keller, AD Wolfe, JD Thomson 2006
Anther dehiscence and pollen production in Penstemon and relatives. Am Nat 167:288-296.

Castellanos MC, P Wilson, JD Thomson 2002 Dynamic nectar replenishment in flowers of Penstemon (Scrophulariaceae). Am J Bot 89:111-118.

2003 Pollen transfer by hummingbirds and bumblebees, and the divergence of pollination modes in Penstemon. Evolution 57: 2742-2752.

2004 "Anti-bee" and "pro-bird" changes during the evolution of hummingbird pollination in Penstemon flowers. J Evol Biol 17: 876-885.

Chittka L, NM Waser 1997 Why red flowers are not invisible to bees. Isr J Plant Sci 45:169-183.

Cnaani JC, JD Thomson, DR Papaj 2006 The effect of reward properties on learning and choice in foraging bumblebees. Ethology 112: 278-285.

Corbet SA 2006 A typology of pollination systems: implications for crop management and the conservation of wild plants. Pages 315340 in NM Waser, J Ollerton, eds. Plant-pollinator interactions: from specialization to generalization. University of Chicago Press, Chicago.

Coyne JA 1995 Speciation in monkeyflowers. Nature 376:726-727.

Cruden RW 1972 Pollinators in high-elevation ecosystems: relative effectiveness of bees and birds. Science 176:1439-1440.

Cruden RW, SM Hermann, S Peterson 1983 Patterns of nectar production and plant-pollinator coevolution. Pages 80-125 in BL Bentley, TS Elias, eds. The biology of nectaries. Columbia University Press, New York.

Darwin C 1862 On the various contrivances by which British and foreign orchids are fertilized. J Murray, London.

Dilley J, P Wilson, MR Mesler 2000 The radiation of Calochortus: generalist flowers moving through a mosaic of potential pollinators. Oikos 89:209-222.

Endler JA 1992 Signals, signal conditions, and the direction of evolution. Am Nat 139(suppl):S125-S153. 
Faegri K, L van der Pijl 1979 Principles of pollination ecology. 3rd ed. Pergamon, Oxford.

Fenster CB, WS Armbruster, MR Dudash, P Wilson, JD Thomson 2004 Floral specialization and pollination syndromes. Annu Rev Ecol Evol Syst 35:375-403.

Fenster CB, G Cheely, MR Dudash, RJ Reynolds 2006 Nectar reward and advertisement in hummingbird-pollinated Silene virginica (Caryophyllaceae). Am J Bot 93:1800-1807.

Fenster CB, MR Dudash 2001 Spatiotemporal variation in the role of hummingbirds as pollinators of Silene virginica. Ecology 82: 844-851.

Fisher RA 1930 The genetical theory of natural selection. Clarendon, Oxford.

Fulton M, SA Hodges 1999 Floral isolation between Aquilegia formosa and Aquilegia pubescens. Proc R Soc B 266:2247-2252.

Futuyma DJ 1998 Evolutionary biology. 3rd ed. Sinauer, Sunderland, MA.

Galetto L, G Bernardello 2004 Floral nectaries, nectar production dynamics and chemical composition in six Ipomoea species (Convolvulaceae) in relation to pollinators. Ann Bot 94:269-280.

Gegear RJ, JG Burns 2007 The birds, the bees, and the virtual flowers: can pollinator behavior drive ecological speciation in flowering plants? Am Nat 170:551-556.

Gilpin ME, ME Soulé 1986 Minimum viable populations: processes of species extinction. Pages 19-34 in ME Soulé, ed. Conservation biology. Sinauer, Sunderland, MA.

Gottlieb LD 1984 Genetics and morphological evolution in plants. Am Nat 123:681-709.

Grant V 1994 Historical development of ornithophily in the western North American flora. Proc Natl Acad Sci USA 91:10407-10411.

Herrera CM 1987 Components of pollination "quality": comparative analysis of a diverse insect assemblage. Oikos 50:79-90.

1996 Floral traits and plant adaptation to insect pollinators: a devil's advocate approach. Pages 65-87 in DG Lloyd, SCH Barrett, eds. Floral biology: studies on floral evolution in animalpollinated plants. Chapman \& Hall, New York.

Hiesey WM, MA Nobs, O Björkman 1971 Experimental studies on the nature of species. V. Biosystematics, genetics, and physiological ecology of the Erythranthe section of Mimulus. Carnegie Inst Wash Publ 628.

Jordan E 2004 Inheritance patterns in floral characters of Penstemon and pollinator preference. MS thesis. California State University, Northridge.

Kay KM 2006 Reproductive isolation between two closely-related hummingbird-pollinated Neotropical gingers. Evolution 60:538552.

Kay KM, PA Reeves, RG Olmstead, DW Schemske 2005 Rapid speciation and the evolution of hummingbird pollination in Neotropical Costus subgenus Costus (Costaceae): evidence from nrDNA ITS and ETS sequencies. Am J Bot 92:1899-1910.

Kay KM, DW Schemske 2003 Pollinator assemblages and visitation rates for 11 species of Neotropical Costus (Costaceae). Biotropica 35:198-207.

Kirkpatrick M, NH Barton 1997 Evolution of a species' range. Am Nat 150:1-23.

Kölreuter JG 1761-1766 Vorläufige Nachricht von einigen das Geschlecht der Pflanzen betreffenden Versuchen und Beobachten. Gleditschischen Handlung, Leipzig.

Losos JB 1992 The evolution of convergent structure in Caribbean Anolis communities. Syst Biol 41:403-420.

Mayfield M, NM Waser, MV Price 2001 Exploring the "most effective pollinator principle" with complex flowers: bumblebees and Ipomopsis aggregata. Ann Bot 88:591-596.

Miller RB 1978 The pollination ecology of Aquilegia elegantula and A. caerulea (Ranunculaceae) in Colorado. Am J Bot 65:406-414.
1981 Hawkmoths and the geographic patterns of floral variation in Aquilegia caerulea. Evolution 35:763-774.

Miller RE, JA McDonald, PS Manos 2004 Systematics of Ipomoea subgenus Quamoclit (Convolvulaceae) based on its sequence data and a Bayesian phylogenetic analysis. Am J Bot 91:1208-1218.

Mitchell RJ, RG Shaw 1993 Heritability of floral traits for the perennial wild flower Penstemon centranthifolius (Scrophulariaceae): clones and crosses. Heredity 71:185-192.

Muchhala N 2006 The pollination biology of Burmeistera (Campanulaceae): specialization and syndromes. Am J Bot 93:1081-1089.

Müller H, F Delpino 1871 Application of the Darwinian theory to flowers and the insects which visit them. Am Nat 5:271-297.

Ollerton J 1996 Reconciling ecological processes with phylogenetic patterns: the apparent paradox of plant-pollinator systems. J Ecol 84:767-769.

Orr HA, JA Coyne 1992 The genetics of adaptation: a reassessment. Am Nat 140:725-742.

Price MV, NM Waser, RE Irwin, DR Campbell, AK Brody 2005 Temporal and spatial variation in pollination of a montane herb: a seven-year study. Ecology 86:2106- 2116.

Rausher MD 2008 Evolutionary transitions in floral color. Int J Plant Sci 169:7-21.

Raven PH 1972 Why are bird-visited flowers predominantly red? Evolution 26:674.

Rodríguez-Gironés MA, L Santamaría 2004 Why are so many bird flowers red? PLoS Biol 2:1515-1519.

Sakai AK, SG Weller, M-L Chen, S-Y Chou, C Tasanont 1997 Evolution of gynodioecy and maintenance of females: the role of inbreeding depression, outcrossing rates, and resource allocation in Schiedea adamantis (Caryophyllaceae). Evolution 51:724-736.

Sargent RD, JC Vamosi 2008 The influence of canopy position, pollinator syndrome, and region on evolutionary transitions in pollinator guild size. Int J Plant Sci 169:39-47.

Schemske DW, HD Bradshaw 1999 Pollinator preference and the evolution of floral traits in monkeyflowers (Mimulus). Proc Natl Acad Sci USA 96:11910-11915.

Schemske DW, CC Horvitz 1984 Variation among floral visitors in pollination ability: a precondition for mutualism specialization. Science 225:519-521.

Simpson MG 2006 Plant systematics. Elsevier, Oxford.

Sprengel CK 1793 Das entdeckte Geheimnis der Natur im Bau und in der Befruchtung der Blumen. Friedrich Vieweg dem aeltern, Berlin.

Stebbins GL 1970 Adaptive radiation of reproductive characteristics in angiosperms. I. Pollination mechanisms. Annu Rev Ecol Syst 1: $307-326$.

1989 Adaptive shifts toward hummingbird pollination. Pages 39-60 in JH Bock, YB Linhart, eds. The evolutionary ecology of plants. Westview, Boulder, CO.

Thompson JN 1994 The coevolutionary process. University of Chicago Press, Chicago.

Thomson JD, P Wilson, M Valenzuela, M Malzone 2000 Pollen presentation and pollinator syndromes, with special reference to Penstemon. Plant Species Biol 15:11-29.

Thomson JD 1978 Effects of stand composition on insect visitation in two-species mixtures of Hieracium. Am Midl Nat 100:431440 .

2003 When is it mutualism? Am Nat 162(suppl):S1-S9.

Thomson JD, BA Thomson 1992 Pollen presentation and viability schedules in animal-pollinated plants: consequences for reproductive success. Pages 1-24 in R Wyatt, ed. Ecology and evolution of plant reproduction: new approaches. Chapman \& Hall, New York.

Waser NM, L Chittka, MV Price, NM Williams, J Ollerton 1996 Generalization in pollination systems, and why it matters. Ecology 77:1043-1060.

Wester P, R Claßen-Bockhoff 2006 Hummingbird pollination in 
Salvia haenkei (Lamiaceae) lacking the typical lever mechanism. Plant Syst Evol 257:133-146.

Whittall JB, SA Hodges 2007 Pollinator shifts drive increasingly long nectar spurs in columbine flowers. Nature 447:706-709.

Wilbert SM, DW Schemske, HD Bradshaw 1997 Floral anthocyanins from two monkeyflower species with different pollinators. Biochem Syst Ecol 25:437-443.

Williams NM, JD Thomson 1998 Trapline foraging by bumble bees. III. Temporal patterning of visits. Behav Ecol 9:612-621.

Wilson P, MC Castellanos, JN Hogue, JD Thomson, WS Armbruster 2004 A multivariate search for pollination syndromes among penstemons. Oikos 104:345-361.

Wilson P, MC Castellanos, AD Wolfe, JD Thomson 2006 Shifts between bee- and bird-pollination among penstemons. Pages 47-68 in NM Waser, J Ollerton, eds. Plant-pollinator interactions: from specialization to generalization. University of Chicago Press, Chicago.

Wilson P, JD Thomson 1996 How do flowers diverge? Pages 88-111 in DG Lloyd, SCH Barrett, eds. Floral biology: studies on floral evolution in animal-pollinated plants. Chapman \& Hall, New York.

Wilson P, AD Wolfe, WS Armbruster, JD Thomson 2007 Constrained lability in floral evolution: counting convergent origins of hummingbird pollination in Penstemon and Keckiella. New Phytol 176: 883-890.

Wolfe AD, SL Datwyler, CP Randle 2002 A phylogenetic and biogeographic analysis of the Cheloneae (Scrophulariaceae) based on ITS and matK sequence data. Syst Bot 27:138-148.

Wolfe AD, CP Randle, SL Datwyler, JJ Morawetz, N Arguedas, J Diaz 2006 Phylogeny, taxonomic affinities, and biogeography of Penstemon (Plantaginaceae) based on ITS and cpDNA sequence data. Am J Bot 94:1699-1713.

Wright SI, RW Ness, JP Foxe, SCH Barrett 2008 Genomic consequences of outcrossing and selfing in plants. Int J Plant Sci 169: 105-118.

Zufall RA, MD Rausher 2004 Genetic changes associated with floral adaptation restrict future evolutionary potential. Nature 428:847850 . 